BULLETIN Bulletin hispanique

HISPANIQUE Université Michel de Montaigne Bordeaux

121-1 | 2019

La épica en el mundo hispánico (Siglo de Oro)

\title{
Andrés Martínez de León, Las crónicas de Oselito en Frente Sur, Frente Extremeño y Frente Rojo. Edición crítica de Rafael ALARCÓN SIERRA
}

Madrid, Escolar \& Mayo Editores 2018

Francisco Javier Díez de Revenga

\section{(2) OpenEdition}

\section{Journals}

Edición electrónica

URL: https://journals.openedition.org/bulletinhispanique/8266

DOI: 10.4000/bulletinhispanique.8266

ISSN: 1775-3821

\section{Editor}

Presses universitaires de Bordeaux

\section{Edición impresa}

Fecha de publicación: 24 junio 2019

Paginación: 392-394

ISBN: 979-10-300-0363-5

ISSN: 0007-4640

Referencia electrónica

Francisco Javier Díez de Revenga, «Andrés Martínez de León, Las crónicas de Oselito en Frente Sur, Frente Extremeño y Frente Rojo. Edición crítica de Rafael alarcón sierra», Bulletin hispanique [En línea], 121-1 | 2019, Publicado el 24 junio 2019, consultado el 04 enero 2023. URL: http:// journals.openedition.org/bulletinhispanique/8266 ; DOI: https://doi.org/10.4000/bulletinhispanique. 8266

Este documento fue generado automáticamente el 4 enero 2023.

All rights reserved 


\title{
Andrés Martínez de León, Las crónicas de Oselito en Frente Sur, Frente Extremeño y Frente Rojo. Edición crítica de Rafael ALARCÓN SIERRA
}

\author{
Madrid, Escolar \& Mayo Editores 2018
}

Francisco Javier Díez de Revenga

\section{REFERENCIA}

Andrés Martínez de León, Las crónicas de Oselito en Frente Sur, Frente Extremeño y Frente Rojo. Edición crítica de Rafael ALARCón SIERRA, Madrid, Escolar \& Mayo Editores 2018, 240 págs. (Literatura y Guerra Civil, 5), ISBN: 978-84-17134-48-8.

1 Supone este libro una interesante y valiosa aportación al conocimiento de los medios de comunicación y difusión que se publicaron durante la Guerra de España y que llevaron a cabo una intensa labor que quedó impresa en unos periódicos y revistas cuyo valor para el conocimiento de aquella época y de las relaciones entre los distintos frentes se ofrece ahora como fundamental. El profesor del Departamento de Filología Española de la Universidad de Jaén Rafael Alarcón Sierra, especialista en literatura española del siglo XX, ha sido el encargado de llevar a cabo la edición crítica y el estudio preliminar de este volumen en el que se recogen las crónicas de Oselito en Frente Sur, Frente Extremeño y Frente Rojo, publicadas por el escritor Andrés Martínez de León y protagonizadas por su personaje Oselito, en Jaén, Castuera y Valencia durante la Guerra Civil.

2 Sobresale en esta edición el extenso y detallado estudio preliminar realizado por el profesor Alarcón porque nos permite conocer la figura tan olvidada del escritor andaluz, nacido en Coria del Río, Andrés Martínez de León (1895-1978), periodista y dibujante, creador de Oselito, pintor y escritor, que fue en su época uno de los cronistas gráficos más importantes ya que participó en multitud de medios periodísticos y 
editoriales $\mathrm{y}$, sobre todo, por su especialización en los dibujos relativos a la tauromaquia y al fútbol, a los que era aficionado de raza. Entre sus obras se destaca el desenfadado y pintoresco, nunca mejor dicho, diario de viaje que realizó a la URSS.

Entre sus amigos, hay que citar, junto a otros muchos, a Blas Infante, Manuel Chaves Nogales, Pedro Garfias, José Herrera Petere o Miguel Hernández, pero lo cierto es que aún hoy es un gran desconocido, no ya en toda España, sino incluso en Andalucía. El destino de sus trabajos gráficos era la efímera presencia en un periódico o en una revista, y el olvido ha sepultado sus creaciones que ahora yacen olvidadas en las hemerotecas. Por eso, el esfuerzo realizado por Rafael Alarcón Sierra es tan oportuno y tan necesario. En su estudio preliminar de más de cien páginas, informa de la vida y de la obra de Martínez de León a lo largo de toda su trayectoria pero especialmente en los años de la Guerra de España. Algunos datos poseen especial relevancia histórica, como las informaciones sobre las ocasiones en que coincide con Miguel Hernández en los frentes de Jaén y de Extremadura y, posteriormente, ya en la Posguerra, en la prisión de Conde de Toreno de Madrid: la literatura y el dibujo fueron afinidades que facilitaron esa relación.

4 Todas las informaciones facilitadas por Alarcón Sierra están apoyadas en una documentación exhaustiva de primera mano, y una completa bibliografía final cierra el estudio introductorio con mención de la obra propia de Martínez de León, de los libros ilustrados por él, de sus publicaciones en prensa durante la Guerra de España y de sus carteles. La bibliografía secundaria completa este enjundioso apartado.

5 Respecto a Oselito hay que señalar que, en efecto, fue un personaje ficticio inventado por el célebre cronista gráfico, que mostraba en sus artículos un derroche de humor e inteligencia sobresalientes, siempre puestos al servicio de la causa republicana. Oselito diminutivo de José, con la velar sorda inicial aspirada, y muy similar al nombre del gran torero andaluz desaparecido poco antes, Joselito, se consagra como un gran analista de la situación social, política y bélica que se está viviendo en los frentes de combate en la Guerra de España.

6 Y de esta forma se presenta el 27 de junio de 1937 al iniciar su colaboración en Frente Extremeño. «He de presentarme. ¿A qué andá jugando a las mascaritas preguntando si me conose o no me conose? Me llamo Oselito, soy de Triana, capital de Sevilla, cuento hasta veinte año y para de contá. Mi estao es más impresionante que un trimotó fasista, pues me hallo a disposición de las empresas: es desí: sortero y buscando compromiso. Antes, desí esto era una verdadera temeridá, pero ahora, a fuersa de andá entre er peligro, no tiene importansia. Son fenómenos de la guerra. [.] Soy hombre curtío por la guerra: er frente de Madrí, er frente andalú, ahora er frente extremeño».

7 Su sentido del humor, su gracia indudable, no empecen ni amortiguan su carácter combativo. Sin duda, la fonética dialectal que utiliza Martínez de León en sus textos contribuye de forma decisiva al tono popular y castizo que define al personaje creado, cuyas ocurrencias se veían reforzadas en su humor por la expresión lingüística local, a la hora de dar cuenta de los hechos más peregrinos que llegaban a su conocimiento, y que él relataba en sus crónicas con desenfadada ocurrencia. Un buen ejemplo podría ser la delirante institución de una especie de parque temático faccioso para recluir en él, como si de un zoo se tratase, a los fascistas en el Santuario de Santa María de la Cabeza. Otro hecho memorable relatado por el cronista podría ser la toma de Sanlúcar por la «Colurna Oselito». 
8 Destaca en la lectura de las crónicas que Oselito escribe sobre todo su inteligente sentido del humor desde el mismo comienzo, en primera persona, cuando da cuenta detallada de su llegada a Jaén y a Castuera, que contrasta con Madrid. A veces sus informaciones revelan datos que en la posteridad alcanzan a poseer cierta trascendencia histórica. Así la información sobre un mitin en Jaén donde interviene Pasionaria, o la detallada crónica de un acto en el que Miguel Hernández recita sus "Aceituneros», sabrosa por sus simpáticas referencias a la propia imagen del poeta de Orihuela, coincidente con todas las descripciones que sobre su figura conservamos: «Er poeta resitaba de pie, impasible, sin gesto, pero sus ojos redondo y asules como bolillas de gaseosa, se fijaba insistentemente en mí desde el pan moreno de su cara».

9 La calidad de las crónicas se ve incrementada por la multitud de descripciones y detalles tomados de la realidad y reflejada con expresivo donaire: paisajes, pueblos, ciudades, mujeres, viajes, caminos, el aceite, la aceituna, los olivos, el viento... todo adquiere una connotación muy singular que revela hasta qué punto el sentido del humor podía contribuir y mucho a la adversidad de los momentos que se viven, que no olvidemos que estaban protagonizados por la guerra y por la muerte.

10 Transcribe Rafael Alarcón Sierra en su edición por orden cronológico las crónicas publicadas por Martínez de León y protagonizadas por Oselito en Frente Sur, Frente Extremeño y Frente Rojo durante la Guerra de España y que nunca se habían reunido en un libro. Anota la procedencia de cada texto y las características gráficas de su publicación.

11 Advierte el editor que, dada la dispersión de este tipo de publicaciones, aún pueden aparecer algunas otras crónicas, ya que no existen colecciones completas de estos periódicos de guerra en ninguno de los archivos oficiales y privados utilizados por el investigador. Como apéndice incluye el artículo publicado por Martínez de León en La Voz el 14 de febrero de 1937, titulado «El humor en la guerra. Muerte temprana de "Oselito"».

12 Respeta totalmente en la transcripción la particular ortografía fonética que quiere representar el habla popular sevillana con el habitual seseo, la pérdida o relajación de las consonantes así como las sustituciones pronominales propias de la expresión local andaluza ubicada en Sevilla o Triana. Destaca en esta edición crítica la profusión y extensión de la anotación a pie de página, que ha realizado el editor para aclarar toda clase de pormenores aludidos en los textos editados. Por último un expresivo apéndice de documentación gráfica reproduce algunas de las páginas de los periódicos transcritas así como una colección de dibujos de guerra de Martínez de León.

13 En definitiva: nos hallamos ante un documento fundamental para conocer mejor no solo los medios de difusión periodísticos bélicos de la Guerra de España, sino porque se tiene la oportunidad además de valorar la obra literaria y gráfica de un escritor muy singular que desarrolló en los años de la guerra su particular contienda periodística llena de gracia y de humor en tiempos muy difíciles y trágicos para todos. 


\section{AUTOR}

FRANCISCO JAVIER DÍEZ DE REVENGA

Universidad de Murcia 